\title{
Linking Knowledge Sharing to Innovative Work Behaviour: The Role of Psychological Empowerment
}

\author{
Abdullah F. ALMULHIM ${ }^{1}$
}

Received: July 03, 2020 Revised: July 25, 2020 Accepted: August 10, 2020

\begin{abstract}
The purpose of the study is to explore the psychological empowerment of the worker as a moderator to explain the link between knowledge sharing and innovative work behaviour within the telecommunication sector of Saudi Arabia. This study is based on a quantitative approach, having collected data through a series of questionnaires developed on previous studies. This study has applied Smart-Partial Least Squares (PLS) for the data analysis. The results revealed that there is a positive and significant relationship between knowledge sharing and innovative work behaviour. The knowledge sharing increases the competencies of the workers, bringing about more creativeness and perfection. Furthermore, this study elaborates that psychological empowerment plays an important role as a moderator in making a strong relationship between knowledge sharing and innovative work behaviour. This study concluded that the innovative work behaviour in any organisation depends on the practice, experience, and capabilities of the workers and, most importantly, the interdepartmental knowledge shared amongst them. The sharing of knowledge psychologically empowers the worker to bring creativity, modernization and excellence in the work that affects the marginal productivity, profitability, and customer satisfaction at a great extent. These factors provide long-run sustainability to business in a highly competitive market environment.
\end{abstract}

Keywords: Knowledge Sharing, Innovative Work Behaviour, Psychological Empowerment, Telecommunication Sector, Saudi Arabia

JEL Classification Code: M10, M12, M19, M16, D8

\section{Introduction}

Innovative work behaviour of workers is an essential element that helps organisations to attain competitive advantage, which in turn provides a guarantee for a long-run existence in the highly competitive business environment. It is also associated with the formation, enlargement, and execution of novel as well as constructive ideas in the organisation (Baer, 2012). Therefore, innovative work behaviour by the employees has become an important focus for all industries in all countries. Within the production processes and development of the business, innovation is known as a fundamental activity that is important for

${ }^{1}$ First Author and Corresponding Author. Assistant Professor, Department of Business Administration, College of Business, Jouf University, Saudi Arabia [Postal Address: P.O. Box 2014, Sakaka, Aljouf, 75471, Saudi Arabia] Email: afalmulhim@ju.edu.sa

(C) Copyright: The Author(s)

This is an Open Access article distributed under the terms of the Creative Commons Attribution Non-Commercial License (https://creativecommons.org/licenses/by-nc/4.0/) which permits unrestricted non-commercial use, distribution, and reproduction in any medium, provided the original work is properly cited. the improvement of active operations (e.g., production, development, and provision of services) and mainly for enhanced business value (Ertürk, 2012; AlMulhim, 2017; Hoang \& Ngoc, 2019). In the current environment, innovative behaviour is a critical path with which the organisation can continue to achieve sustainable development. It also acts as a significant element for attaining competitive advantage and improved managerial performance (Gomes \& Wojahn, 2017; Phong, Hui, \& Son, 2018). There are many elements that affect the growth and development of any organisation, such as leadership style, use of technology, training, etc., but for the innovative behaviour of the employees in the firm, knowledge sharing is an essential factor. According to organisational learning theory, knowledge sharing effectively promotes innovative work behaviour (Crossan, 1996). Knowledge sharing has become recognisable as a procedure where workers exchange knowledge and information by the mean of discussions to generate new ideas and create innovation in the workplace (Van den Hooff \& Ridder, 2004). It also helps the employees to comprehend their careers in a more meaningful way and bring personal recognition within the department (Cheng, 2002). Knowledge sharing not only 
effect the individuals in the enterprises, but also accelerates over all the performance of the business and profitability (Muafi, 2020).

On the other side, knowledge sharing has an extensive and intense impact on the psychology of the workers. There is an expectation that a psychologically empowered worker will have a tendency to be more dynamic in sharing knowledge and innovative work behaviour within firms, organisations, or any institution (Kang, Lee, \& Kim, 2017). It also allows workers to perform multiple tasks and assume greater responsibility within the firm, and it has a significant influence on attaining improvements at work. It increases the self-sufficiency and ability of the worker to do their job more professionally (Paré \& Tremblay, 2007). Therefore, the main aim of the study is to find out the associations among the knowledge sharing, innovative work behaviour, and psychological empowerment, because these variables are gaining importance in worldwide markets. Current business requirements emphasise the need to find the relationship among the above-mentioned variables in a service-providing organisation such as telecommunications by using the psychological empowerment of the workers as a moderator.

There are different studies that attempted to find the actual relationship between the knowledge sharing and innovative work behaviour. However, these previous studies have some gaps; for example, these studies have failed to completely expose the different aspects and forms of knowledge sharing on worker's innovative activity. No persuasive, reliable termination point has been drawn in the conclusions of the aforesaid research works. For example, in knowledge sharing, some researchers assumed that knowledge sharing had an inverse impact on innovation (Hass \& Hansen, 2007), whereas the studies of others concluded that it had positive influences on the innovative behaviour of employee (Wang, Yang, \& Liu, 2010). Taking into consideration the dilemma mentioned above, a limited number of scholars have explained the knowledge sharing from the behaviour-oriented point of view. To resolve the weaknesses of previous research, this study developed the following research questions; the answers to these questions have provided assistance to accomplish the objectives of the studies.

RQ1: Is there any relationship between knowledge sharing and innovative work behaviour?

RQ2: Does psychological empowerment inhibit or increase knowledge sharing and innovative work behaviour?

On the basis of these questions, this study gave a manifold contribution to the research world. First of all, this paper has put the scholar's objective forward by using this categorisation to study knowledge sharing and innovative work behaviour. Second, to cover the above-mentioned gap, the current study has found the nexus concerning the relationship between knowledge sharing and innovative work behaviour in the telecommunication sector in Saudi Arabia, and it has used psychological empowerment as a moderator, which has never been incorporated in previous studies. Third, there are some theories like Social Exchange Theory (SET), Theory of Planned Behaviour (TBP), Theory of Reasoned Action (TRA) and Technology Acceptance Model (TAM) which are primarily used to understand human behaviour (Aliakbar, Yusoff, \& Mahmood, 2012). These theories are known as a critical base of the psychological level of the workers to understand an individual's knowledge sharing behaviour. The current study has found the theoretical foundation of knowledge sharing and by using the social cognitive theory.

\section{Literature Review}

\subsection{Social Cognitive Theory}

Social cognitive theory (SCT) is an essential theory in multiple disciplines such as psychology, management, education, and communication. This theory explains that part of knowledge-gaining of a person directly connects to others by the observation of social relations, experiences, and exterior media influence. This SCT has its foundation as the Social Learning Theory developed by Albert Bandura in 1960. Further, this theory evolved into the SCT in 1986 and posits that knowledge takes place in a social framework with dynamic and reciprocal relations of the individual, surroundings, and behaviour. The important components of the SCT connected to revolutionising individual behaviour are noted as "self-efficacy, behavioural capability, expectations, expectancies, and self-control: observational learning and reinforcements".

The SCT explains the connections of cognitive dynamics, behavioural factors, environmental factors, and personal factors in manipulating how an individual selfmotivates and acts or performs in an organisation (Crothers, Hughes, \& Morine, 2008). Additionally, this theory explains that individuals should constantly manage knowledge by the means of discussion, transformation, recombination, and distribution of tacit knowledge to display innovative behaviour (Nonaka, 1994; Quintane, Casselman, Reiche, \& Nylund, 2011; Teixeira, Oliveira, \& Curado, 2018; AlMulhim, 2020). The SCT indicates that a person can be motivated to carry out a particular task based on how he/she would assess their competence (or behaviour) and their prospect on the completion of their actions (Bandura, 1986, 1997). There are many scholars who have extended the building blocks of SCT to a different aspect of human and organisational functioning as well as work behaviour (Wood \& Bandura, 1989; Lent, Brown, \& Hackett, 1994; Ifinedo, Cashin, \& Ojo, 2014). Among the core concepts associated with the $\mathrm{SCT}$, the framework is knowledge sharing, innovative work 
behaviour, and psychological empowerment of workers. These concepts are explained below.

\subsection{Knowledge Sharing}

Knowledge sharing is related to the exchange of information, experience, or to give additional awareness to the worker about the task (Wang \& Noe, 2010; Ha, 2020). The concept of knowledge sharing has become an essential part of the production process and economic development. According to some supporters of the knowledge-based views (KBV), it is an intangible source that provides the ground work of competitive advantage, and it increases the efficiency of the workers as well as the organisation in the production environment (Ferlie et al., 2015; Alguezaui \& Filieri, 2014). There are two types of employees (experienced and new) in any organisation, and the collaboration and teamwork between the workers make the organisation more profitable and successful. Knowledge sharing is very helpful to assist the partners or workers to resolve their difficulties, execute policies, or expand novel ideas. The creativity and successes of the individual or firm are based on the advanced strategy of the working process that can be attained by the sharing of knowledge (Li \& Sandino, 2018). Knowledge sharing effectively increases job satisfaction of the workers and bring innovation in their work (Hoa, Thanh, Mai, Le Van, \& Quyen, 2020). For this purpose, the workers circulate their attained knowledge to others within an institute for accomplishing the different tasks. This activity enables the lesser experienced workers to use their expertise in a productive manner (Ryu, Ho, \& Han, 2003).

\subsection{Innovative Work Behaviour}

Innovative work behaviour is the procedure of identifying, encouraging, realising, and implementing an idea within a particular operation in an organisation that gives the benefits of improved performance at the individual, cluster, and organisation levels (West \& Farr, 1990). In other words, the innovative behaviour is also known as identification and application of new technologies or strategies of work to augment the existing tasks (Yuan \& Woodman, 2010).

Innovation is a significant element for the organisation to be successful in the market and to attain the objective of sustainable growth ( $\mathrm{Liu}, \mathrm{Du}, \& \mathrm{Ai}, 2016$ ). For the existence and sustainability of the firm in this chaotic market environment, a firm requires continuous innovation in its production process and management $(\mathrm{Li}, \mathrm{Du}$, Tang, Boadu, \& Xue, 2019). Therefore, with the passage of time, the innovative work behaviour has become one of the main channels that provide sustainable development to the organisation, and it plays a significant role in achieving competitive benefit, improved managerial performance, and introducing the new production methods (Gomes \& Wojahn, 2017; Phong, Hui, \& Son, 2018).

\subsection{Psychological Empowerment}

Psychological empowerment has gained intensive popularity in the area of management over the last few years. It provides a sense of responsibility and increases the efficiency of the workers (Spreitzer, 1995; Gautam $\&$ Ghimire, 2017). The empowerment of the worker is the keystone of innovative processes in any organisation. Empowerment increases the administration practices, and it empowers the workers through different means, such as the delegation of decision making and access to information, thereby providing resources for the employees at a lower level of the organisation and increasing the overall work efficiency (Ripley \& Ripley, 1992). The empowerment of the employees allows them to perform numerous tasks with efficiency and more responsibilities, and it has a great influence at work while enjoying increased independence (Paré \& Tremblay, 2007). Dan, Xu, Liu, Hou, Liu, and Ma, (2018) and Hebenstreit (2012) have found a positive relationship between empowerment and innovative behaviour. Knowledge sharing and innovative work behaviour, with the moderating effects of psychological empowerment, are getting increased worldwide recognition of its importance. It is a requirement of the current situation to find the relationship among the above-mentioned variables in an organisation.

\section{Research Hypothesis}

This study has developed the research hypothesis to identify the link between knowledge sharing with the workers, and, in return, the worker's innovative work behaviour presented to the organisation. This study has proposed and assessed the importance of knowledge received and the moderating role of the psychological empowerment in the link between knowledge sharing and innovative work behaviour.

\subsection{Knowledge Sharing and Innovative Work Behaviour}

Nowadays, the technologies have made the access of information boundary-less, and enterprises have pushed towards continuous innovation, which is the main driver for sustainable development as well as economic benefits (Dadfar, Dahlgaard, Brege, \& Alamirhoor, 2013; Özçelik \& Taymaz, 2004). The competition among the different enterprises has increased (Distanont \& Orapan, 2019). The innovative behaviour of the employee is very critical to any firm for sustainable development (Tu, Wang, He, \& Zhang, 2017). 


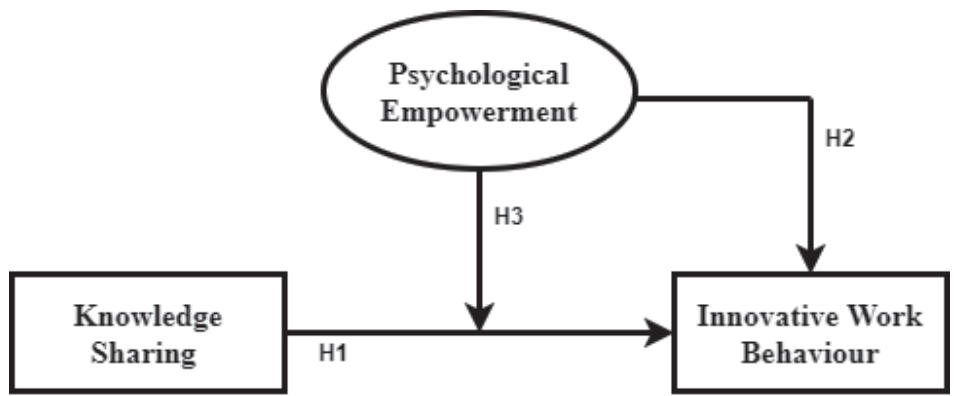

Figure 1: Proposed model of the study

In this situation, if the organisations are unsuccessful in implementing innovation in their production strategy, then these organisations would lose their potential ability to beat the competitors in the marketplace and eventually run the risk of going out of the market (Shanker, Bhanugopan, Van der Heijden, \& Farrell, 2017). But this innovation progression depends on some factors like knowledge sharing and knowledge transformation, practice, inventiveness, and the capability of employees; these factors are important for continuous awareness about creating new ideas (De Jong \& Den Hartog, 2007). Among these elements, knowledge sharing has a strong link for promoting the innovative behaviour of an employee in the organisation (Kang et al., 2017; Crossan, 1996). On the base of the above discussion, this study hypothesises that:

H1: Knowledge sharing has a positive relation with innovative work behaviour.

\subsection{Psychological Empowerment and Innovative Work Behaviour}

Psychological empowerment of the worker is an important factor that encourages the innovative behaviour of the workers in any organisation. It innovates the ideas of production (Marane, 2012; Seibert, Wang, \& Courtright, 2011; Singh \& Sarkar, 2012, 2019). Psychological empowerment is related to an individual mental position, which is characterised by the wisdom of authority with a strong motivation and high capability to complete the expectation at the organisation (Spreitzer, 1995). The psychologically empowered employees demonstrate more innovative behaviour and an ability to perform the task efficiently (Afsar, Cheema, \& Bin Saeed, 2018; Spreitzer, 1995; Amabile \& Gryskiewicz, 1989). Therefore, a worker with empowerment will tend to be more energetic in sharing knowledge, and will endorse innovative work behaviour (Kang et al., 2017). Therefore, this study hypothesises that:

H2: Psychological empowerment has a positive relation with innovative work behaviour.

\subsection{Moderating Effect of Psychological Empowerment}

Knowledge sharing is known as a primary tool for encouraging innovative behaviour and performance in workers (Wang, Tan, Cheng, \& Wong, 2015). The worker shares the experience, gives suggestions, translates information, and resolves the problem by implementing these ideas (Zhu \& Mu, 2016). This practice of knowledge sharing motivates the participation of workers in innovative work behaviour. This knowledge sharing empowers the workers to bring novelty to the production process. Therefore, empowerment is seen as a dynamic of innovative behaviour (Fernandez \& Moldogaziev, 2013; Brunetto \& Farr-Wharton, 2007). The exercise of empowerment stimulates the workforce to allocate their expertise to make the organisation successful. The empowerment of the worker plays the important role linking the knowledge sharing and innovative behaviour as the psychological empowered employees use to demonstrate more innovative behaviour and the ability to perform the task more efficiently (Afsar et al., 2018; Spreitzer, 1995; Amabile \& Gryskiewicz, 1989). Therefore, the psychologically empowered worker tends to be more vigorous in sharing knowledge, and can endorse innovative work behaviour effectively (Kang et al., 2017). On this base, the study hypothesises that:

H3: Psychological empowerment moderates the link between the knowledge sharing and innovative work behaviour among workers in Saudi Arabia.

\section{Research Methodology}

\subsection{Sampling and Data Collection}

The data for analysis was collected from telecommunications enterprises in Saudi Arabia. To increase the level of the response rate, this questionnaire was translated into the Arabic language too. First of all, an incentive e-mail was sent to the administrative names to inform them of the project, and ask about their 
willingness to contribute to the survey. The procedure for questionnaire distribution was online, including a letter of direction and a statement of confidentiality of data to all the targeted respondents. The basis for the survey, potential advantages, and confidential aspects of the survey were detailed to participants. The response of the administrative body was encouraging, and they gave permission to proceed with the next phase. Second, the study collects data randomly from the respondents. For collecting the data, this study uploaded the questionnaire on the web page. The website link of the questionnaire was also sent to the possible respondents. Finally, six hundred questionnaires were distributed, and, in return, only 332 responses were received from these enterprises. Among these 332 responses, a few had missing information, and some these had incomplete information. This study had to remove data from those questionnaires for better analysis. In the end, only 324 responses were found valid for the analysis. This study received a $54 \%$ response rate from the potential participants. This participation rate is favourable for research of such a nature. This survey was organised from December 2, 2019, to January 30, 2020.

Regarding the telecommunications sector, it has a crucial part of economic development along with business, agricultural, industrial, health, and educational sectors (Ali $\&$ Haque, 2017). The aims of this study behind selecting this sector are following:

- First, telecommunication service sectors are innovation-intensive, and for innovation, its services needed knowledge-intensive activities.

- Second, the workers of this sector need up to date knowledge and previous experience to satisfy the consumer's needs and questions and provide solutions to the dynamic problems in working.

- Third, the workers in the company's headquarters are more autonomous than workers in the franchises for performing innovatively in their work; therefore, allowing them increased opportunities for generating, sharing, and utilising the knowledge can make the company more profitable.

- Fourth, the companies of this sector require workers with at least 16 years of education. The additional education for these workers is required to perform knowledge-based tasks with perfection and effectively.

- Fifth, this study selected this sector to study the link between the knowledge-sharing worker's innovative behaviour (that is essential to meet the needs of the customers and to beat the competitors in this business field) of different enterprises.

- Sixth, this sector is selected to investigate the presence of the social cognitive theory in this sector. The aim of this study in selecting this sector is to explore the psychological empowerment of the workers, and its moderating role for the knowledge sharing and innovative work behaviour.

- Finally, these companies are the principal indicators of development in any country. These industries improve the employment level and participate in national income generation. Therefore, it is crucial to explore the study to analyse the important elements that affects the productivity of this sector.

\subsection{Measures}

This study used a contextualised version of Scott and Bruce (1994) by using six items for innovative work behaviour; for example, "I am innovative" and "I generate creative ideas". For measuring the knowledge sharing, this study also used four items introduced by Huang (2009). These items are, for example, "I always share my manuals, models, and methodologies". The dimensions of the psychological empowerment consisted of the 12 items introduced by Spreitzer (1995). This study used four sub-dimensions, such as meaning, competence, self-determination, and impact. All the instruments are measured on 5-point Likert Scale (1= strongly agree; $5=$ strongly disagree).

\section{Results}

The results of this study have extracted through the Smart PLS software by using PLS (partial least square techniques). The PLS method has benefits to adjust the latent variables for reflective or formative construction. This method also reduces the limitations related to sample size (Terzi, Trezzini, \& Moroni, 2014; Lee, Chen, Tsui, \& Yu, 2014). This study used two-stage approaches and developed the hierarchical component model (Ringle, Sarstedt, \& Straub, 2012). In the first stage, the assessment, validity, and reliability of the proposed model were examined, and the second stage explained the structural model.

Table 1 explained the demographic characteristics of participating employee, such as gender, age, education level, management level, and experience. This table explained that the participants are only male $(100 \%)$; for the education level, $26.5 \%$ were less than bachelor, $59.3 \%$ were bachelor degree holder, and $14.2 \%$ had a master's degree or above. According to the management level of the participant, $10.8 \%$ were working in top management, $55.2 \%$ in middle management, and $34.0 \%$ in lower management.

The discriminate validity of the variable is explained in Table 2. This table indicates the exclusivity of each independent, which is created from another. The square root of average variance extracted (AVE) is greater than the construct's correlations (Hair, Black, Babin, \& Anderson, 2014; Hair, Hult, Ringle, \& Sarstedt, 2017; Hair, Anderson, Tatham, \& Black, 2010). 
Table 1: Demographic characteristic of participating employees

\begin{tabular}{|c|c|c|c|}
\hline \multicolumn{2}{|c|}{ Demographic characteristic } & \multirow{2}{*}{$\begin{array}{c}\text { Frequency } \\
324\end{array}$} & \multirow{2}{*}{$\begin{array}{c}\text { Percent } \\
100\end{array}$} \\
\hline & Male & & \\
\hline torior & Female & 0 & 0 \\
\hline \multirow{4}{*}{ Age } & 20-30 years & 63 & 19.5 \\
\hline & $31-40$ years & 151 & 46.6 \\
\hline & $41-50$ years & 96 & 29.6 \\
\hline & More than 50 years & 14 & 4.3 \\
\hline \multirow{3}{*}{ Education level } & Less than bachelor & 86 & 26.5 \\
\hline & Bachelor & 192 & 59.3 \\
\hline & Master degree or above & 46 & 14.2 \\
\hline \multirow{3}{*}{ Management level } & Top management & 35 & 10.8 \\
\hline & Middle management & 179 & 55.2 \\
\hline & Lower management & 110 & 34.0 \\
\hline \multirow{5}{*}{ Experience } & Less than 1 year & 21 & 6.5 \\
\hline & $1-5$ years & 45 & 13.9 \\
\hline & $6-10$ years & 85 & 26.2 \\
\hline & $11-20$ years & 122 & 37.7 \\
\hline & More than 20 years & 51 & 15.7 \\
\hline
\end{tabular}

Table 2: Discriminate validity

\begin{tabular}{|l|c|c|c|c|c|}
\hline Variables & AVE & CR & $\mathbf{1}$ & $\mathbf{2}$ & $\mathbf{3}$ \\
\hline Innovative Work Behaviour & 0.749 & 0.900 & 0.841 & & \\
\hline Knowledge Sharing & 0.707 & 0.923 & 0.683 & 0.865 & \\
\hline Psychological Empowerment & 0.770 & 0.964 & 0.820 & 0.577 & 0.878 \\
\hline
\end{tabular}

Further, Table 2 demonstrates that there is no correlation estimation among the construct. Consequently, all variables presented in the model are discriminately valid. Table 3 explains the convergent validity, $\mathrm{R}$ square, and factor loading of the latent variables. The value of the $\mathrm{R}$ square indicates the fitness of the model. Additionally, convergent validity indicates the appropriateness of constructs and the purpose of measurement. According to research, the value should not be less than 0.50 of AVE (Hair et al., 2017). This current study does not face any problem with validity of convergence, because the smallest value of the average variance extracted is 0.707 (Innovative Work Behavior).

Table 3 also presents the composite reliability values of the variable. This table explained that the CR (composite reliability) is greater than 0.70 . This value shows that reliability and a high level of consistency (Nunnally \& Bernstein, 1994). This convergent validity explains the level of the proposed model. According to this value, the result indicates a high level of convergent validity. It means the model is a good fit. 
Table 3: Convergent validity of research constructs

\begin{tabular}{|c|c|c|c|c|}
\hline Latent variable & Items & Loadings & AVE & CR \\
\hline \multirow{3}{*}{ Knowledge Sharing } & KS1 & 0.867 & \multirow{3}{*}{0.749} & \multirow{3}{*}{0.900} \\
\hline & KS2 & 0.848 & & \\
\hline & KS3 & 0.881 & & \\
\hline \multirow{5}{*}{ Innovative Work Behaviour } & IWB 1 & 0.881 & \multirow{5}{*}{0.707} & \multirow{5}{*}{0.923} \\
\hline & IWB 2 & 0.696 & & \\
\hline & IWB 3 & 0.861 & & \\
\hline & IWB 4 & 0.917 & & \\
\hline & IWB 5 & 0.831 & & \\
\hline \multirow{8}{*}{ Psychological Empowerment } & PE10 & 0.901 & \multirow{8}{*}{0.770} & \multirow{8}{*}{0.964} \\
\hline & PE11 & 0.882 & & \\
\hline & PE12 & 0.838 & & \\
\hline & PE3 & 0.835 & & \\
\hline & PE5 & 0.856 & & \\
\hline & PE7 & 0.903 & & \\
\hline & PE8 & 0.906 & & \\
\hline & PE9 & 0.896 & & \\
\hline \multicolumn{5}{|c|}{ (R square) $R^{2} 0.740$} \\
\hline
\end{tabular}

Table 4: Direct relationship and moderation

\begin{tabular}{|c|c|c|c|c|c|c|}
\hline Hypothesis & Relationship & Beta & Standard error & T-value & P-value & Decision \\
\hline H1 & KS > IWB & 0.315 & 0.047 & 6.685 & 0.000 & Supported \\
\hline H2 & PE > IWB & 0.590 & 0.049 & 12.119 & 0.000 & Supported \\
\hline H3 & KS ${ }^{*}$ PE > IWB & 0.118 & 0.025 & 4.648 & 0.000 & Supported \\
\hline
\end{tabular}

\subsection{Relationships and Moderation with Hypothesis}

Table 4 explains the direct relationship and moderating effects of the variable. The table shows that association between the knowledge sharing and innovative work behaviour are highly significant because the $\beta=0.315$ and $p$ $<0.000$. This result is supporting $\mathrm{H}_{1}$.

Similarly, the $\beta$ value of the $\mathrm{H}_{2}$ is 0.590 and $\mathrm{p}<0.000$. This result indicates that psychological empowerment and innovative work behaviour have a highly significant relationship. Further, this table unveils that the $\mathrm{H}_{3}$ is 0.118 and $\mathrm{p}<0.000$, also supported by the result. This result indicates that the psychological empowerment plays a positive and significant role as moderator between the knowledge sharing and innovative work behaviour of workers.

\subsection{Moderating Effect of Psychological Empowerment}

Figure 2 indicates the moderating effect of psychological empowerment. This figure explains that psychological empowerment has a positive as well as a significant moderating effect between knowledge sharing and innovative work behaviour.

\section{Discussion}

The present study seeks the link between knowledge sharing and innovative work behaviour and moderating effect of the psychological empowerment of the worker in the telecommunications sector. Further, this study has developed three hypotheses to find out the theoretical foundation of the variables. The results are summarised in tables 1 to 4 . 


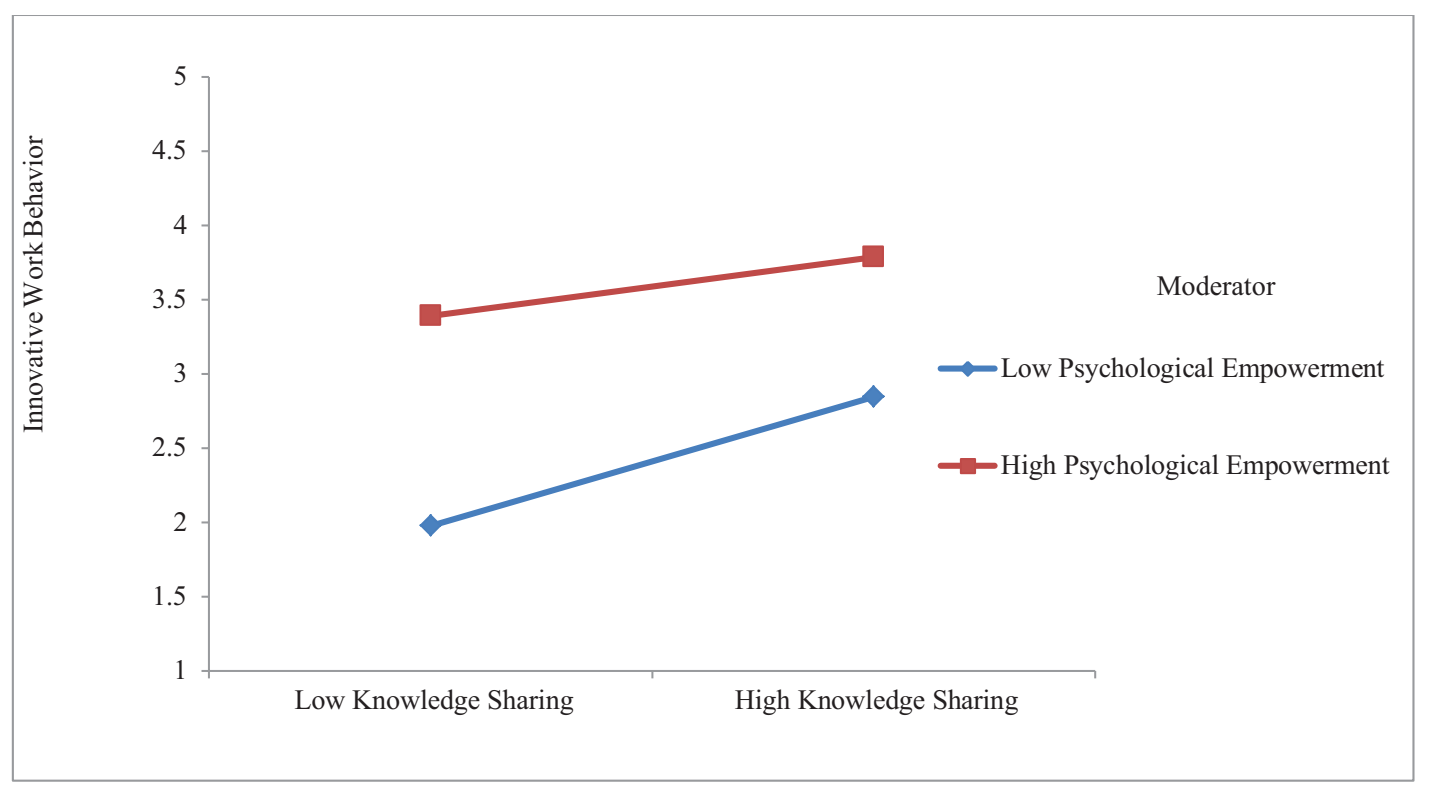

Figure 2: Moderating effect of worker's psychological empowerment

This study has accepted the first null hypothesis (H1), which explains the positive link between the knowledge sharing and innovative work behaviour of the workers and tests have supported this hypothesis. The result is consistent with the previous study (Helmy, Adawiyah, \& Banani, 2019; Kang et al., 2017; Jilani, Fan, Islam, \& Uddin, 2020). According to De Jong and Den Hartog (2007), the innovation in any organisation depends on the practice, experience, and capabilities of workers. The knowledge sharing helps the workers to create more new ideas in product procedures (Jadhav, Seetharaman, \& Rai, 2017). The concept of knowledge sharing is not new. It is a crucial part of business globally because knowledge sharing makes the employees more efficient working either inside or outside the organisation. It increases the work capacities, innovation in production, or service of the worker, as well as the organisation in the world market (Wang \& Noe, 2010; Helmy et al., 2019). It is important for any organisation to have better communications, accessibility of market information, and a positive trend of knowledge sharing within the organisation to predict the consumer's behaviour in the future and bring the possible innovations in production or service ideas (Troy, Szymanski, \& Varadarajan, 2001).

The second hypothesis, $\mathrm{H} 2$, of this study is also accepted. It finds that psychological empowerment has a significant and positive influence on innovative work behaviour. If workers are intensely provided with the best knowledge sharing for their psychological empowerment by the company or by other experienced persons within the organisation, they will be able to improve and enlarge their productivity and will initiate more advanced ideas, bringing innovation to their project or work. According to the investigation of Sangar and Rangnekar (2014), if the worker has freedom of decision-making, then they can generate new ideas to avoid the risks and delays and thereby increasing the productivity. The empowerment brings the onset of the innovation not only in their behaviour but in the organisation as well.

The $\mathrm{H} 3$ elaborates the moderating effect of psychological empowerment between knowledge sharing and innovative work behaviour in the telecommunication industry in Saudi Arabia. The psychological empowerment acts as the bridge between the knowledge sharing and utilisation of this knowledge in a productive way and for innovative work behaviour. Subsequently, this current study endorses the viewpoint which encourages manpower as a fundamental factor in the workplace to enhance the productivity of the enterprise or developing and delivering any inventiveness for revolutionising the workplace. The psychologically empowered workers can generate new ideas and support the execution of such ideas. In this method, the empowered workers bring forth the much-required vibrancy in productivity (Singh \& Sarkar, 2019).

\subsection{Theoretical Implementation}

This study has a theoretical implementation of the finding extracted by analysis. This study is following the social cognitive theory and broadens the acquaintance by hypothesising that psychological empowerment can act as a moderator for making the positive and significant link 
between knowledge sharing and innovative work behaviour. From the theoretical approach, this study strengthens the telecommunication sector in a different way. For example, the telecommunication sector needs innovation with the passage of time. The innovation develops the productivity of the company, and it also increases the reliability of the consumer with that company (Bohlin \& Brousseau, 2001). The user connected to a telecommunication sector requires up-to-date service. The finding of this study indicates that if the organisation transfers its concentration to knowledge sharing, this knowledge sharing will decrease the risk of loss because it will psychologically empower the workers and bring innovation in work. The result of this study is supported by social cognitive theory. Finally, the current findings expand the understanding of knowledge sharing and psychological empowerment as a predictor of innovative behaviour, and it is ready to explore additional issues about innovative work behaviour.

\subsection{Practical Implementations}

The finding of this study explains that sharing knowledge facilitates and engages the employees in more traditional or ambidextrous actions (Jilani et al., 2020). Particularly, these results are applicable to the telecommunication enterprise, because the knowledge sharing enables the workers to solve the problems related to performance and bring innovation to the working style. Usually, a telecommunication sector has a desire to retain active clients by constantly improving their way of service providing. At the same time, these enterprises want to stay practical by motivating their employees to the predicted customer's requirements in the future, innovation in products or services, and to explore the path for enhancing productivity. The findings of this study further revealed that an organisation should arrange training sessions from time to time for empowering the employee psychologically; the psychological empowerment will lead the sense of knowledge sharing in an employee. Knowledge could compose of extra value and resources for the advancement of organisations (Jeon, Rosalen, Falsetta, \& Koo, 2011) and further opportunity to increase the performance level to maximise productivity and benefits.

\section{Limitations and Future Research}

There are some limitations to be discussed surrounding the study. Firstly, it used an accurate time-lagged design, but a longitudinal approach is needed to inspect the link between knowledge sharing, innovative work behaviour, and psychological empowerment. The knowledge sharing among the workers used to fluctuate in different periods of time with the changing of resources (Jilani et al., 2020), and its impact on innovation then varied in response; therefore, it is compulsory to inspect knowledge sharing and innovation over a longer period of time. Second, this study collects the data from Saudi Arabia for the analysis; the working environment of the organisation is different from that of a Western culture. Advanced research should observe if the results have similarities in developing counties or within the Western world. Third, this study has focused on the three main variables: knowledge sharing, innovative behaviour, and psychological empowerment. But future studies can identify the motivational benefits of knowledge sharing by examining the function of leadership, (for example, transactional, transformational, or ethical leadership) in the innovative behaviour of the employee. Finally, there are many other social variables that can affect innovative work behaviour and the exchange of knowledge, and these variables can also be used as moderators (e.g., personal growth, workload, etc.). The finding, conclusions, and implementation are limited by the perspective of the research; it is believed that informative validation of the results of the current study by a future study would measure this concept with the same data, but in a different context. This study also suggests that different companies should arrange communication between the employees of the same department with different groups. The organisations should organise different seminars, and expert persons and motivators should visit other branches to share their experiences. This type of social loop can increase the capacity to generate a new idea.

\section{Conclusion}

This study maps out to find the link between knowledge sharing and innovative work behaviour through the moderating effect of the psychological empowerment of the workers. This study has selected the telecommunication sector of Saudi Arabia for the analysis. The finding of the study elaborates the positive and significant link between knowledge sharing and innovative work behaviour, and it also found the positive and significant moderating effect of psychological empowerment in the telecom industry in Saudi Arabia. This study answers both research questions that there is a positive and significant link between knowledge sharing and innovative work behaviour and secondly, psychological empowerment enables the workers to execute the innovative strategy and ensures knowledge sharing within the organisation.

\section{References}

Afsar, B., Cheema, S., \& Bin Saeed, B. (2018). Do nurses display innovative work behavior when their values match with hospitals values? European Journal of Innovation Management, 21(1), 157-171. https://doi.org/10.1108/ejim-01-2017-0007

Alguezaui, S., \& Filieri, R. (2014). A knowledge-based view of the extending enterprise for enhancing a collaborative 
innovation advantage. International Journal of Agile Systems and Management, 7(2), 116-131. https://doi.org/10.1504/ ijasm.2014.061434

Ali, A., \& Haque, M. (2017). Telecommunication sector of Saudi Arabia: Internal and external analysis. Academy of Accounting and Financial Studies Journal, 21(3), 2017.

Aliakbar, E., Yusoff, R. B. M. \& Mahmood, N. H. N. (2012). Determinates of knowledge sharing behavior. International Conference on Economics, Business and Marketing Managementt CEBMM (pp. 208-215). Singapore City, Singapore, February 26-28. Singapore: IACSIT Press.

AlMulhim, A. F. (2020). The effect of tacit knowledge and organisational learning on financial performance in the service industry. Management Science Letters, 10(10), 2211-2220. https://doi.org/10.5267/j.msl.2020.3.015

AlMulhim, A. F. (2017). The effects of knowledge creation process on organisational performance: Evidence from Saudi banking sector. International Journal of Management Sciences and Business Research, 6(1), 11-22.

Amabile, T. M., \& Gryskiewicz, N. D. (1989). The creative environment scales: Work environment inventory. Creativity Research Journal, 2(4), 231-253. https://doi. org/10.1080/10400418909534321

Baer, M. (2012). Putting creativity to work: the implementation of creative ideas in organisations. Academy of Management Journal, 55(5), 1102-1119. https://doi.org/10.5465/ amj.2009.0470

Bandura, A. (1997). Self-efficacy: The Exercise of Control. New York, NY: Freeman.

Bandura, A. (1986). Social Foundations of Thought and Action: A social Cognitive Theory. Englewood Cliffs, NJ: Prentice-Hall.

Bohlin, E. \& Brousseau, E. (2001). Innovation in the telecommunications industry. Economics of Innovation and New Technology, 10(2), 73-87. https://doi. org/10.1080/10438590100000004

Brunetto, Y., \& Farr-Wharton, R. (2007). The moderating role of trust in SME owner/managers 'decision-making about collaboration. Journal of Small Business Management, 45(3), 362-387. https://doi.org/10.1111/j.1540-627x.2007.00218.x

Cheng, M. Y. (2002) Socialising knowledge management: The influence of the opinion leader. Journal of Knowledge Management Practice, 3(3), 76-83.

Crossan, M. (1996). The Knowledge-Creating Company: How Japanese companies create the dynamics of innovation. Journal of International Business Studies, 27(1), 196-201. https://doi. org/10.1057/jibs.1996.13

Crothers, L. M., Hughes, T. L., \& Morine, K. A. (2008). Theory and Causes in School-based Consultations. A Resource for School Psychologists, School Counselors, Special Educators, and Mental Health Professionals. New York, NY: Routledge Taylor \& Francis Group.
Dadfar, H., Dahlgaard, J. J., Brege, S., \& Alamirhoor, A. (2013). Linkage between organisational innovation capability, product platform development and performance: The case of pharmaceutical small and medium enterprises in Iran. Total Quality Management \& Business Excellence, 24(7-8), 819-834. https://doi.org/10.1080/14783363.2013.791102

Dan, X., Xu, S., Liu, J., Hou, R., Liu, Y., \& Ma, H. (2018). Relationships among structural empowerment, innovative behaviour, self-efficacy, and career success in nursing field in mainland China. International Journal of Nursing Practice, 24(5), 12674. https://doi.org/10.1111/ijn.12674

De Jong, J. P. J., \& Den Hartog, D. N. (2007). How leaders influence employees' innovative behaviour. European Journal of Innovation Management, 10(1), 41-64. https://doi. org/10.1108/14601060710720546

Distanont, A., \& Orapan, K. (2019). The role of innovation in creating a competitive advantage. Kasetsart Journal of Social Sciences, 40(1), 1-7.

Ertürk, A. (2012). Linking psychological empowerment to innovation capability: Investigating the moderating effect of supervisory trust. International Journal of Business and Social Science, 3(14), 153-165.

Ferlie, E., Crilly, T., Jashapara, A., Trenholm, S., Peckham, A., \& Currie, G. (2015). Knowledge mobilization in healthcare organisations: A view from the resource-based view of the firm. International Journal of Health Policy and Management, 4(3), 127-130. https://doi.org/10.15171/ijhpm.2015.35

Fernandez, S., \& Moldogaziev, T. (2013). Using employee empowerment to encourage innovative behavior in the public sector. Journal of Public Administration Research and Theory, 23(1), 155-187. https://doi.org/10.1093/jopart/mus008

Gautam,D.K., \& Ghimire, S.B.(2017). Psychological empowerment of employees for competitive advantages. International Journal of Law and Management, 59(4), 466-488. https://doi. org/10.1108/ijlma-03-2016-0035

Gomes, G., \& Wojahn, R. M. (2017). Organizational learning capability, innovation and performance: study in small and medium-sized enterprises (SMES). Revista de Administração (São Paulo), 52(2), 163-175. https://doi.org/10.1016/j. rausp.2016.12.003

Hair, J. F. Jr., Black, W. C., Babin, B. J., \& Anderson, R. E. (2014). Multivariate Data Analysis: A Global Perspective ( $7^{\text {th }}$ ed.). Harlow, UK: Pearson.

Hair, J. F. Jr., Hult, G. T. M., Ringle, C. M., \& Sarstedt, M. A. (2017). Primer on Partial Least Squares Structural Equation Modeling (PLS-SEM). Thousand Oaks, CA: Sage Publication, Inc.

Hair, J. F. Jr., Anderson, R. E., Tatham, R. L., \& Black, W. C. (2010). Multivariate Data Analysis. Upper Saddle River, NJ: Prentice Hall.

Hass, M. R., \& Hansen, M. T. (2007). Different knowledge, different benefits: Toward a productivity perspective on 
knowledge sharing in organisations. Strategic Management Journal, 28(11), 1133-1153. https://doi.org/10.1002/smj.631

Hebenstreit, J. J. (2012). Nurse educator perceptions of structural empowerment and innovative behaviour. Nursing Education Perspectives, 33(5), 297-301. https://doi.org/10.5480/15365026-33.5.297

Helmy, I., Adawiyah, W. R., \& Banani, A. (2019). Linking psychological empowerment, knowledge sharing, and employees 'innovative behavior in SMEs. The Journal of Behavioral Science, 14(2), 66-79?

Huang, C. C. (2009). Knowledge sharing and group cohesiveness on performance: An empirical study of technology R\&D teams in Taiwan. Technovation, 29(11), 786-797. https://doi. $\operatorname{org} / 10.1016 / j$.technovation.2009.04.003

Ha, V. D. (2020). The impacts of empowerment on the teamwork performance: Evidence from commercial banks in Vietnam. Journal of Asian Finance, Economics and Business, 7(4), 267-273. https://doi.org/10.13106/jafeb.2020.vol7.no4.267

Ifinedo P, Cashin J., \& Ojo, O. (2014). Social-cognitive mechanisms and counterproductive computer security behaviors (CCSB): An analysis of links. Proceedings of the 44th Atlantic Schools of Business conference (pp 138-152). September 26-28. Halifax, Canada: Mount Saint Vincent University.

Jeon, J. G., Rosalen, P. L., Falsetta, M. L., \& Koo, H. (2011). Natural products in caries research: Current (limited) knowledge, challenges and future perspective. Caries Research, 45(3), 243-263. https://doi.org/10.1159/000327250

Jilani, M. M. A. K., Fan, L., Islam, M. T., \& Uddin, M. (2020). The influence of knowledge sharing on sustainable performance: A moderated mediation study. Sustainability, 12(3), 908. https:// doi.org/10.3390/su12030908

KKang, Y. J., Lee, J. Y., \& Kim, H. W. (2017). A psychological empowerment approach to online knowledge sharing. Computers in Human Behavior, 74, 175-187. https:// doi.org/10.1016/j.chb.2017.04.039

Lee, C. S., Chen, Y. C., Tsui, P. L., \& Yu, T. H. (2014). Examining the relations between open innovation climate and job satisfaction with a PLS path model. Quality \& Quantity, 48(3), 1705-1722. https://doi.org/10.1007/s11135-013-9869-6

Lent, R., Brown, S.D., \& Hackett, G. (1994). Toward a unifying social cognitive theory of career and academic interest, choice, and performance, Journal of Vocational Behavior, 45(1), 79-122. https://doi.org/10.1006/jvbe.1994.1027

Li, R., Du, Y. F., Tang, H. J., Boadu, F., \& Xue, M. (2019). MNEs'subsidiary HRM practices and firm innovative performance: A tacit knowledge approach. Sustainability, 11(5), 1388. https://doi.org/10.3390/su11051388

Li, S. X., \& Sandino, T. (2018). Effects of an information sharing system on employee creativity, engagement, and performance. Journal of Accounting Research, 56(2), 713-747. https://doi.org/10.1111/1475-679x.12202

Liu, L. L., Du, R., \& Ai, S. Z. (2016). Impact of culture on the relationship between knowledge sharing and innovative behavior in IT services industry. Chinese Journal of Management Science, 24(4), 159-166.

Marane, B. M. (2012). The mediating role of trust in organisation on the influence of psychological empowerment on innovation behavior. European Journal of Social Sciences, 33(1), 39-51.

Muafi, M. (2020). A nexus among strategic orientation, social network, knowledge sharing, organizational innovation, and MSMEs performance. Journal of Asian Finance Economics and Business, 7(6), 327-338. https://doi.org/10.13106/ jafeb.2020.vol7.no6.327

Nonaka, I. (1994). A dynamic theory of organisational knowledge creation. Organization Science 5(1), 14-37. https://doi. org/10.1287/orsc.5.1.14

Nunnally, J. C., \& Bernstein, I. H. (1994). Psychometric Theory ( $3^{\text {rd }}$ ed.). New York, NY: McGraw-Hill.

Hoa, N. D., Thanh, V. B., Mai, V. T., Le Van, T. U. N. G., \& Quyen, H. V. T. (2020). Knowledge sharing influence on innovation: A case of textile and garment enterprises in Vietnam. Journal of Asian Finance, Economics and Business, 7(7), 555-563. https:// doi.org/10.13106/jafeb.2020.vol7.no7.555

Hoang, C. C., \& Ngoc, B. H. (2019). The relationship between innovation capability and firm's performance in electronic companies, Vietnam. Journal of Asian Finance, Economics and Business, 6(3), 295-304. https://doi.org/10.13106/jafeb.2019. vol6.no3.295

Özçelik, E., \& Taymaz, E. (2004). Does innovativeness matter for international competitiveness in developing countries? The case of Turkish manufacturing industries. Research Policy, 33(3), 409-424. https://doi.org/10.1016/j.respol.2003.09.011

Paré, G., \& Tremblay, M. (2007). The influence of high-involvement human resources practices, procedural justice, organisational commitment, and citizenship behaviors on information technology professionals 'turnover intentions. Group \& Organization Management, 32(3), 326-357. https://doi. org/10.1177/1059601106286875

Phong, L. B., Hui, L., \& Son, T. T. (2018). How leadership and trust in leaders foster employees' behavior toward knowledge sharing. Social Behavior and Personality: An International Journal, 46(5), 705-720. https://doi.org/10.2224/sbp.6711

Quintane E., Casselman R. M., Reiche, S., \& Nylund, P. A. (2011). Innovation as a knowledge-based outcome. Journal of Knowledge Management, 15(6): 928-947. https://doi. org/10.1108/13673271111179299

Ringle, C. M., Sarstedt, M., \& Straub, D. (2012). A critical look at the use of PLS-SEM in MIS Quarterly. MIS Quarterly, 36(1), iii-xiv. https://doi.org/10.2307/41410402

Ripley, R. E., \& Ripley, M. J. (1992). Empowerment, the cornerstone of quality: Empowering management in innovative organisations in the 1990s. Management Decision, 30(4), 20-43. https://doi.org/10.1108/00251749210014743

Ryu, S., Ho, S. H., \& Han, I. (2003). Knowledge sharing behavior of physicians in hospitals. Expert Systems with Applications, 25(1), 113-122. https://doi.org/10.1016/s0957-4174(03)00011-3 
Sangar, R., \& Rangnekar, S. (2014). Psychological empowerment and role satisfaction as determinants of creativity. Asia-Pacific Journal of Management Research and Innovation, 10(2), 119-127. https://doi.org/10.1177/2319510x14536110

Scott, S. G., \& Bruce, R. A. (1994). Determinants of innovative behavior: A path model of individual innovation in the workplace. Academy of Management Journal, 37(3), 580-607. https://doi.org/10.2307/256701

Seibert, S. E., Wang, G., \& Courtright, S. H. (2011). Antecedents and consequences of psychological and team empowerment in organisations: A meta-analytic review. Journal of Applied Psychology, 96(5), 981. https://doi.org/10.1037/a0022676

Shanker, R., Bhanugopan, R., Van der Heijden, B. I., \& Farrell, M. (2017). Organisational climate for innovation and organisational performance: The mediating effect of innovative work behavior. Journal of Vocational Behavior, 100, 67-77. https://doi.org/10.1016/j.jvb.2017.02.004

Singh, M., \& Sarkar, A. (2012). The relationship between psychological empowerment and innovative behavior: A dimensional analysis with job involvement as mediator. Journal of Personnel Psychology, 11(3), 127-137. https://doi. org/10.1027/1866-5888/a000065

Singh, M., \& Sarkar, A. (2019). Role of psychological empowerment in the relationship between structural empowerment and innovative behaviour. Management Research Review, 42(4), 521-538. https://doi.org/10.1108/mrr-04-2018-0158

Spreitzer, G.M. (1995). Psychological empowerment in the workplace: Dimensions, measurement, and validation. Academy of Management Journal, 38(5), 1442-1465. https:// doi.org/10.5465/256865

Teixeira, E. K., Oliveira, M., \& Curado, C. M. M. (2018). Knowledge management process arrangements and their impact on innovation. Business Information Review, 35(1), 29-38. https://doi.org/10.1177/0266382118757771

Terzi, S., Trezzini, A., \& Moroni, L. (2014). A PLS path model to investigate the relations between institutions and human development. Quality \& Quantity, 48(3), 1271-1290. https:// doi.org/10.1007/s11135-013-9834-4

Troy, L. C., Szymanski, D. M., \& Varadarajan, P. R. (2001). Generating new product ideas: An initial investigation of the role of market information and organisational characteristics. Journal of the Academy of Marketing Science, 29(1), 89. https://doi.org/10.1177/0092070301291006
Tu, X. Y., Wang, Z. Y., He, X., \& Zhang, Q. (2017). Critical thinking, creative process engagement and innovation behavior: The empirical study of Technology-Based enterprises. Science of Science and Management of S\&T (China), 38(3), 126-138.

Van Den Hooff, B., \& De Ridder, J. A. (2004). Knowledge sharing in context: The influence of organisational commitment, communication climate and CMC use on knowledge sharing. Journal of Knowledge Management, 8(6), 117-130. https://doi. org/10.1108/13673270410567675

Jadhav, V., Seetharaman, A., \& Rai, S. (2017). Employee expectation to demonstrate innovative work behaviour in Asia. Journal of Asian Finance, Economics and Business, 4(1), 67-78. https:// doi.org/10.13106/jafeb.2017.vol4.no1.67

Wong, K. Y., Tan, L. P., Lee, C. S., \& Wong, W. P. (2015). Knowledge management performance measurement: Measures, approaches, trends and future directions. Information Development, 31(3), 239-257. https://doi.org/10.1177/0266666913513278

Wang, M. H., Yang, T. Y. \& Liu, P. C., (2010). The impact of knowledge sharing and projects complexity on team creativity: An example of information systems development. Journal of e-Business (China), 12(1), 73-102.

Wang, S., \& Noe, R. A. (2010). Knowledge sharing: A review and directions for future research. Human Resource Management Review, 20(2), 115-131. https://doi.org/10.1016/j. hrmr.2009.10.001

West, M. A., \& Farr, J. L. (1990). Innovation and Creativity at Work: Psychological and Organisational Strategies. Chichester, UK: John Wiley'?

Wood, R. E., \& Bandura, A. (1989). Social cognitive theory of organisational management. Academy of Management Review, 14(3), 361-384. https://doi.org/10.5465/amr.1989.4279067

Yuan, F., \& Woodman, R. W. (2010). Innovative behaviour in the workplace: The role of performance and image outcome expectations. Academy of Management Journal, 53(2), 323-342. https://doi.org/10.5465/amj.2010.49388995

Zhu, C., \& Mu, R. (2016). Followers 'innovative behavior in organisations: The role of transformational leadership, psychological capital and knowledge sharing. Frontiers of Business Research in China, 10(4), 636-663. Available at: http://journal.hep.com.cn/fbr/EN/10.3868/s070-005-0160023-0 